\title{
Crisis en el financiamiento de las universidades PÚBLICAS ESPAÑOLAS: ¿VERDAD O DEMAGOGIA?
}

\author{
CRisis in the finAncing of Spanish Public Universities: \\ ¿TRUE O DEMAGOGUERY?
}

Ph.D. Gabriel Ramírez Torres . Universidad Católica Andrés Bello, (UCAB), Caracas, Venezuela.

Ph.D. Luis Morales La Paz Universidad Católica Andrés Bello, (UCAB), Caracas, Venezuela.

Fecha de recepción: 08/05/2016 Fecha de Aceptación: 17/08/2016

\begin{abstract}
Resumen
Con la finalidad de analizar el comportamiento del financiamiento de las instituciones de educación superior en España, por parte de los gobiernos autónomos se analiza un período de la evolución cuatro años antes y cuatro años después de que estallara la crisis en ese país. Se parte de la explicación de la situación de esas instituciones, se describe de forma global los aspectos relevantes que conforman la manera de financiarse las universidades, de acuerdo a lo establecido en la normativa legal de ese país. Con la finalidad de verificar si han
\end{abstract}


disminuido los recursos financieros asignados a esas casas de estudio por parte de las comunidades autónomas de las que dependen, se realiza un análisis estadístico que considerando el comportamiento de determinadas variables y mediante análisis de regresión múltiple se determinaron las variables significativas en los presupuestos de las mismas y posteriormente, haciendo uso de elementos de estadística paramétrica, contraste de hipótesis y análisis de varianza mediante la F-Snedecor, así como análisis de coeficiente de correlación de las variables se llega a conclusiones contrarias a lo sostenido por informes de la organización comisiones obreras.

Palabras clave: financiación, universidades, déficit, crisis.

\begin{abstract}
With the purpose of analyzing the behavior of the financing of the institutions of higher education in Spain, it is important to analyze the evolution, four years before and four years after the outbreak of the crisis in that country about the money that universities got from their autonomous governments. Part of the explanation of the situation of these institutions describes in a comprehensive way the relevant aspects that form the way of financing the universities, according to the established in the legal regulations of that country. In order to verify if the financial resources assigned to these study houses by the autonomous communities on which they depend have decreased, a statistical analysis is performed, considering the behavior of certain variables and by means of multiple regression analysis, the variables significant in the budgets of the same and later, making use of elements of parametric statistics, hypothesis contrast and analysis of variance through the F-Snedecor, as well as analysis of coefficient of correlation of the variables, it arrives at conclusions contrary to the sustained by reports of the Spanish organization of working commissions.
\end{abstract}

Key words Keywords: funding, universities, deficit, crisis. 


\section{Introducción}

La Universidad desde hace varios años dejó de ser un lugar quieto dedicado sólo a la enseñanza, a la escolaridad, a la meditación en paz y a la contemplación del universo como en los siglos pasados. Es un gran centro, complejo, demandante, competitivo que requiere a gran escala de continuas inversiones (OECD IMHE-HEFCE, 2004, pág. 21).

Uno de los pilares básicos para que las universidades cumplan su función de crear conocimientos, - así como la exportación de los mismos al resto del mundo -, lo constituye la manera que tienen esas casas de estudios superiores de generar los recursos necesarios que garanticen su permanencia en el tiempo.

Es por esa razón que en la actualidad hay un reto mayor para que al mismo tiempo que esas instituciones produzcan y cumplan con sus objetivos, logren ser sostenibles.

Dada la complicada situación económica en que se encuentran la mayoría de los países hoy en día, resulta de gran interés analizar la evolución del financiamiento de las universidades públicas españolas, ver si los recursos presupuestados para esas casas de estudios han variado en los últimos años, no sólo en términos absolutos, sino considerando que si ha habido alguna variación, si la misma se puede considerar como significativa, de acuerdo a determinado nivel de significación.

La crisis económica iniciada en Estados Unidos en el año 2007, tuvo repercusiones a nivel mundial, con énfasis particular en España, donde a partir del año 2008 ha habido una situación de deterioro económico más que evidente.

La repercusión que ha tenido esa situación en España y en cada una de sus Comunidades Autónomas, CCAA, no ha dejado libre a muchas instituciones que dependen en mayor o menor medida de los diferentes gobiernos regionales, como lo es el caso de las universidades públicas.

Así mismo, resulta interesante comprobar lo planteado en un trabajo reciente de la Confederación Sindical de Comisiones Obreras española (CCOO), en el que señala que ha habido una disminución significativa de los recursos asignados a las universidades de ese país, o si se trata más de un mito y de manejos políticos. 
El análisis a desarrollar, se realiza considerando la evolución de una series de variables como los presupuestos asignados a las universidades públicas españolas; el Producto Interno Bruto (PIB) de las CCAA, así como la proporción de los presupuestos en el PIB de las regiones en tres períodos, a saber: año 2004 (cuatro años antes que se manifestara formalmente la crisis en España); año 2008 (año de manifestación de la crisis, o al menos el inicio de la misma) y el año 2012 (cuatro años después de iniciada la crisis en ese país).

Lo que se busca es verificar, con la información disponible de las variables antes referidas, si existen diferencias significativas en los presupuestos aprobados por las CCAA españolas en años previos, durante y posteriores a la crisis económica manifestada en ese país.

La investigación aquí considerada se sustenta en la fusión de metodologías. Por una parte, se presenta un estado de la cuestión basado en la revisión de fuentes documentales, es decir, consultas de investigaciones recientes, la revisión y análisis de textos, así como de ensayos y artículos publicados en revistas especializadas en el tema de la educación superior y su financiación. Asímismo, se consideran las leyes y el uso de datos cuantitativos, a la vez que se incorporan las opiniones de investigadores en aspectos específicos relacionados con el tema.

Por otro lado, se procede al análisis estadístico de la información de las distintas casas de estudio, no sólo desde la consideración descriptiva de cuadros presentados, sino más desde la perspectiva de contrastar hipótesis para verificar si hay o no diferencia significativa en los recursos asignados a las universidades y si los mismos han variado en los tres momentos analizados.

Igualmente, se realiza un análisis comparativo, considerando semejanzas y diferencias de la situación de distintas CCAA en cuanto a las variables consideradas, así como un análisis vertical (información de los presupuestos asignados a las universidades en un momento específico), como un análisis horizontal, considerando la variación de los recursos para distintos años.

El presente trabajo se desarrolla en cuatro secciones. En el primer capítulo, se hace una descripción muy general de la evolución del financiamiento de las casas de estudios superiores en España. En el capítulo II se analizan los mecanismos tradicionales de financiación de las instituciones de educación superior en España, considerando los recursos otorgados por el Estado, matrículas de los estudiantes, fundaciones benéfico-docentes y mecenazgos, organismos multilaterales, aportaciones empresariales, entre otros; así como los sistemas empleados por esas instituciones para obtener sus ingresos. En el tercer capítulo, por su parte, se explica de una forma muy general los aspectos más relevantes de la cronología de la crisis vivida en España desde su origen en el 2008 hasta el año 2012.

En el último capítulo se evalúan y explican los datos mediante el uso de análisis estadístico, tanto de la estadística descriptiva, como la definición de las variables a ser analizadas, determinadas mediante una regresión múltiple. De las variables consideradas se hace uso de elementos de estadística paramétrica, contraste de hipótesis y análisis de varianza mediante la F-Snedecor, así como análisis de coeficiente de correlación de las variables. Así mismo, se hace referencia a las fuentes consultadas, las cuales fueron fundamentalmente textos de metodología de la investigación, de estadística entre otros. 
En la última sección del trabajo se presentan las conclusiones a que se llegó con la investigación, además de considerar las posibles líneas de investigación que se podrían continuar, a partir de este estudio del financiamiento de las universidades en España.

\section{1.- Evolución del financiamiento de la educación superior en España}

La educación superior en la península ibérica es una de las más antiguas del mundo, dado que autores como Rodríguez, Cándido y Hernández (1990) coinciden en que de las cuatro primeras universidades en Europa con las características que las conocemos y las definimos hoy día fueron las de Bolonia, Oxford, París y Salamanca - estaba una española. Asimismo, existen estudios que señalan la existencia de otra casa de estudios en Palencia. Si bien esto ocurrió así, la misma no sobrevivió en el tiempo y se extinguió casi en la misma época en que empezaba a desarrollarse la escuela salmantina.

Las universidades eran creadas por mandatos de reyes, con el apoyo o soporte financiero tanto de sus respectivas instituciones, como de la iglesia católica. Se tiene que la Universidad de Salamanca, por ejemplo, fue fundada entre los años 1218 y 1219 por el rey Alfonso IX, y fue él quien la dotó con rentas propias, así como de una incipiente organización, procurando su financiación, con recursos provenientes de las rentas eclesiásticas de los diezmos.

Asimismo, a través de decisiones papales, la Corona también confirmaba los privilegios, como tradicionalmente lo habían hecho los distintos reyes que gobernaron entre los siglo XIII y XVII de acuerdo a lo señalado en el referido texto de Águeda Rodríguez.

De esa manera se evidencia que desde su creación, las universidades se fueron desarrollando con la ayuda de lo que se podía considerar como el poder estatal de la época, la monarquía, a la vez que se tomaban en cuenta las relaciones de ésta con la iglesia católica. Igualmente, desde sus comienzos se tuvo la conciencia de que esas casas de estudios requerían de recursos económicos, por lo que se les otorgó rentas propias para que efectuaran las funciones que se esperaban de ellas.

Las universidades en general y las españolas en lo particular han atravesado por períodos de abundancia y de crisis en la obtención de sus recursos desde su creación hasta nuestros días.

Durante varios siglos, la principal fuente de financiación de esas casas de estudios fueron las Tercias, que eran la tercera parte de las rentas eclesiásticas proveniente de los diezmos. Con la desaparición de los diezmos en el siglo XIX, la hacienda universitaria tuvo que someterse al proceso de centralización que había establecido la hacienda liberal, situación que constituyó de alguna manera el inicio de la incursión del Estado, tal como lo entendemos hoy día, dentro de la actividad universitaria, no sólo en lo económico, sino también en su operación académica.

Un hito al cual se debe hacer referencia en la asignación de recursos de las universidades españolas es que como consecuencia de la situación económica que se vivió en España a finales del siglo XVIII, vemos que a 
mediados del siglo XIX el modelo de financiación universitario tuvo que recurrir al cobro de matrículas, como elemento que le permitiese disponer de mayores ingresos económicos para su existencia; siendo éste un aspecto que cada vez ha ido cobrando mayor importancia dentro del esquema de captación de recursos dentro de las casas de estudios superiores aún en nuestros días.

Las primeras décadas del siglo XX en España se vieron marcadas por una serie de sucesos que afectaron el desarrollo del mundo educativo en general y el universitario en particular, dada la instauración del período de la Primera República en 1873, la restauración monárquica y posteriormente, la conformación de la Segunda República y su ulterior caída por la Guerra Civil que tuvo lugar entre los años 1936 y 1939.

Una vez culminada dicha guerra, se entra en un período dictatorial que abarca desde 1939 hasta la muerte del General Francisco Franco en 1977. En la década de los cincuenta y principio de los sesenta, se tiene que las tasas y subvenciones constituían en promedio hasta un $65 \%$ de los ingresos de las universidades según RODRÍGUEZ-SAN PEDRO BEZARES y POLO RODRÍGUEZ (2004), situación que no cambió significativamente a lo largo de los siguientes años, lo que refleja también la poca importancia que le daba el régimen dictatorial a la educación superior.

En la década de los setenta, se empezó a dar un cambio significativo en el financiamiento universitario con la aprobación de la Ley General de Educación y Financiamiento de la Reforma Educativa (1970), así como con el inicio del proceso de transición en España. Esto se refleja en una mayor participación del Estado dentro de las aportaciones realizadas a las universidades públicas.

Un aspecto relevante que se considera en la Ley en cuestión es que se establece que las universidades estarían sometidas al control jurisdiccional del Tribunal de Cuentas del Reino, a la vez que las mismas deberían formular una Memoria de sus resultados, así como los balances y cuentas, los cuales debían ser aprobados por el gobierno, adaptándose a un presupuesto de carácter anual, el cual debía estar coordinado con los presupuestos generales del Estado. A su vez, cada Universidad elaboraría su presupuesto y lo sometería a las instancias del Ministerio de Educación, así como al Ministerio de Hacienda.

Una crítica que se realizó a esta Ley es que se mantenía la rigidez en la elaboración del presupuesto que dependía de las instrucciones del Ministerio de Hacienda, a la vez que no consideraba los efectos inflacionarios a lo largo de los años, ni tampoco la consideración de la cantidad de alumnos o de centros.

Asimismo, la Ley de 1970 consideraba que para la consecución de sus objetivos, el Estado podía otorgar créditos adicionales necesarios requeridos por las universidades para su financiación.

La Ley de Reforma Universitaria (11/1983) fue aprobada sobre la base de tres principios constitucionales recogidos en el Artículo $\mathrm{N}^{\circ} 27$ que establece el derecho de todos los españoles a la educación, a la libertad de educación y a la autonomía universitaria.

Esta Ley introdujo grandes cambios en el marco de operación de las universidades españolas, las cuales hasta ese momento habían sido completamente controladas por el gobierno central. A partir de esa legislación, los centros 
universitarios pasaron a depender de los gobiernos de las CCAA. Esa decisión hizo que el poder fuera transferido de la burocracia estatal a cuerpos colegiados con significante representación académica y estudiantil.

En la referida Ley, se hace mayor referencia a los aspectos de actuación dentro de las universidades, dado que se otorgó cierta autonomía universitaria, traspasando a las autonomías las competencias en planificación y financiación de centros universitarios. La autonomía financiera se presenta en la existencia, o no, de un presupuesto propio con independencia en su elaboración, aprobación, ejecución, modificación, fiscalización y liquidación - actividades que serían realizadas por sus instancias internas -, así como un detalle de todos los ingresos que se deberían reflejar en el presupuesto de las instituciones de educación superior (Ley 11/1983).

La Ley de Reforma Universitaria citada incorpora una instancia nueva en la estructura de las universidades, el Consejo Social, que es el órgano de participación de la sociedad en la Universidad y el cual tiene entres sus funciones principales el aprobar el presupuesto, la supervisión de las actividades de carácter económico de la Universidad y del rendimiento de sus servicios, así como promover la colaboración de la sociedad en el financiamiento de esas casas de estudios.

En Diciembre del año 2001, las cortes aprobaron la Ley Orgánica de Universidades, LOU (Ley Orgánica 6/2001, de 21 de diciembre, de Universidades. BOE No 307) como resultado de la expansión de la institución universitaria en España en las últimas tres décadas. El propósito fundamental de esta Ley es impulsar la acción de la Administración General del Estado en el sistema universitario, así como profundizar en las competencias de las CCAA en materia de enseñanza superior y fortalecer las relaciones entre la Universidad y la Sociedad.

Es de resaltar que en dicha Ley Orgánica se incorporó un Título, el undécimo, denominado "Del Régimen Económico y Financiero de las Universidades Públicas", en el cual se presentan seis Artículos que hacen referencia a la Autonomía Económica y Financiera de las Universidades, así como al Patrimonio y Presupuestos de esas casas de estudios superiores.

En los mismos se destaca que las universidades públicas tendrán autonomía económica y financiera, por lo que deberán disponer de los recursos suficientes para el ejercicio de sus funciones, para lo cual se regirán tanto por esta Ley, como por la legislación aplicable al sector público.

En relación al Patrimonio de la Universidad, la LOU mantiene que el mismo está constituido por el conjunto de bienes, derechos y obligaciones de cada Universidad. Igualmente, dicha norma contempla la Programación y Presupuestos para esas casas de estudios, lo que se evidencia en su Artículo 81 que señala que las universidades podrán elaborar programaciones plurianuales que puedan conducir a la aprobación, por las CCAA, de convenios y contratos-programa que incluirán sus objetivos, financiación y la evaluación del cumplimiento de los mismos.

Cabe señalar que en el parágrafo tercero de la referida Ley en su Artículo 81, se hace mención a todos los aspectos considerados como ingresos de las universidades dentro de su presupuesto: 
El presupuesto de las Universidades contendrá en su estado de ingresos:

a) Las transferencias para gastos corrientes y de capital fijadas, anualmente, por las CCAA.

b) Los ingresos por los precios públicos por servicios académicos y demás derechos que legalmente se establezcan. En el caso de estudios conducentes a la obtención de títulos de carácter oficial y validez en todo el territorio nacional, los precios públicos y derechos los fijará la Comunidad Autónoma, dentro de los límites que establezca el Consejo de Coordinación Universitaria que estarán relacionados con los costos de prestación del servicio. Asímismo, se consignarán las compensaciones correspondientes a los importes derivados de las exenciones y reducciones que legalmente se dispongan en materia de precios públicos y demás derechos.

c) Los precios de enseñanzas propias, cursos de especialización y los referentes a las demás actividades autorizadas a las Universidades se atendrán a lo que establezca el Consejo Social, debiendo ser, en todo caso, aprobados junto con los presupuestos anuales en los que se deban aplicar.

d) Los ingresos procedentes de transferencias de entidades públicas y privadas, así como de herencias, legados o donaciones.

e) Los rendimientos procedentes de su patrimonio y de aquellas otras actividades económicas que desarrollen según lo previsto en esta Ley y en sus propios Estatutos.

f) Todos los ingresos procedentes de los contratos previstos en el artículo 83.

g) Los remanentes de tesorería y cualquier otro ingreso.

h) El producto de las operaciones de crédito que concierten, debiendo ser compensado para la consecución del necesario equilibrio presupuestario de la Comunidad Autónoma, la cual, en todo caso, deberá autorizar cualquier operación de endeudamiento.

De lo antes referido, se tiene que se ha incrementado la cantidad de partidas que contemplan los recursos posibles para el desarrollo de la institución universitaria. Tal es el caso de que en la Ley del año 2001 se consideren dentro de los ingresos de esos centros universitarios los remanentes de tesorería, así como el producto de operaciones de crédito, que son aspectos que no habían sido considerado dentro de los tipos de ingresos definidos en las leyes anteriores.

En el apartado b) del Artículo $\mathrm{N}^{\circ} 81$ se hace referencia a que las tasas académicas tienen la consideración de precios públicos, por lo que, en virtud de lo dispuesto en las leyes de las CCAA, cada una de ellas fijarán anualmente mediante un Decreto el establecimiento o modificación que debe realizarse de esas Tasas y Precios Públicos. 
Cabe destacar que las universidades entregarán a sus respectivas CCAA para su aprobación, la realización de sus presupuestos de acuerdo a las normas que se establezcan para el sector público, así como informes que especifiquen la relación de puestos de trabajo de las diferentes categorías de la Universidad, los costos de personal docente e investigador, entre otras. Asimismo, las casas de estudios superiores están obligadas a rendir cuentas de sus actividades ante el órgano de fiscalización de cuentas de la Comunidad Autónoma.

El 21 de Enero del 2005 se promulgó el Real Decreto N ${ }^{\circ}$ 55/2005, por el que se establece la estructura de las enseñanzas universitarias y se regulan los estudios universitarios oficiales de Grado, con la finalidad de realizar los ajustes que se deben hacer para la construcción del Espacio Europeo de la Educación Superior, EEES, considerado en la Declaración de Bolonia, así como en las Conferencias de Praga (2001) y Berlín (2003).

La relación que dicho decreto tiene con el financiamiento de la educación superior en España se señala en su Artículo $\mathrm{N}^{\circ} 4$ (REAL DECRETO No 55/2005, de 21 de enero. Publicado en el BOE No 21).

"Precios públicos de las enseñanzas universitarias.

Los estudios conducentes a la obtención de títulos de carácter oficial y validez en todo el territorio nacional e impartidos en Universidades públicas estarán sometidos al régimen de precios públicos que, en el ámbito de sus competencias, establezcan las CCAA de acuerdo con lo establecido en el artículo 81 de la Ley Orgánica 6/2001, de 21 de diciembre, de Universidades".

De lo anterior se concluye que cada autonomía de España deberá establecer anualmente los Precios Públicos correspondientes a los derechos de matrícula en enseñanza oficial, derechos de alojamiento, restauración y residencia, derechos de matrículas en cursos y seminarios, entradas a museos, exposiciones y espectáculos, entre otros; que forman parte del presupuesto de ingresos de las universidades.

Los ingresos por tasas académicas entre 1970 hasta el año 2004 promedian entre el $20 \%$ y el $22 \%$ del total que perciben las universidades, mientras que las transferencias corrientes y de capital, que proceden fundamentalmente del Estado, constituyen cerca del $75 \%$ de los aportes, situación que como se hará referencia posteriormente, no varía significativamente desde el 2004 al 2013, de acuerdo a la página electrónica del Instituto Nacional de Estadísticas (INE, 2014) sección educación universitaria.

En abril del 2012 se publicó el Real Decreto 14/2012, en el que se realizaron algunas modificaciones a lo establecido en la Ley Orgánica de Universidades del 2001, en materia de aprobación presupuestaria en la que se establece que en los presupuestos de las universidades se debe señalar un monto máximo de los gastos a ser ejecutados por ejercicio o año.

En el caso particular de los ingresos presupuestados, en dicho decreto se aprueba que los precios públicos por servicios académicos los fijará cada CCAA, e igualmente se establecen unos rangos de hasta qué porcentaje podrían cubrir esos precios públicos dependiendo del grado académico que curse el estudiante. 


\section{2.- Financiamiento de la educación superior pública española}

\section{1.- Contexto del financiamiento de las universidades españolas}

El financiamiento de las universidades ha venido cobrando cada vez más relevancia en los diferentes sectores de los países de América, Europa y Asia, dada la contribución y los aportes de las instituciones universitarias a los sistemas productivos y a la sociedad en general.

En los últimos tiempos se ve una mayor participación de diversos agentes interesados en contribuir con el desenvolvimiento no sólo académico, sino financiero de las universidades, quienes son las principales oferentes de este tipo de servicios educativo.

La manera de financiar a la enseñanza superior en su conjunto, puede ser considerada como un problema desde el punto de vista económico, dado que por una parte, se tienen las dificultades que existen para lograr sus fines y objetivos; mientras que por la otra, la forma de financiación puede ser considerada como un instrumento del que disponen los poderes públicos para influir en las actividades de las universidades, específicamente en su autonomía o manera de desenvolverse.

Como se evidencia, la Comunidad Autónoma de Andalucía es la que tiene el mayor número de casas de educación superior públicas en España con 10 universidades, seguida de las comunidades de Cataluña y Madrid con 7 universidades públicas cada una. Por su parte, comunidades como Aragón, Castilla La Mancha, Extremadura, Islas Baleares, Comunidad Floral de Navarra, La Rioja, Principado de Asturias y el País Vasco, cuentan con una sola universidad pública en sus respectivas entidades administrativas.

En el análisis que se realiza del financiamiento de las universidades, se parte de una consideración de los objetivos, de los principios, de los sistemas de financiación, de las alternativas y formas que se tienen para financiar principalmente la oferta de este nivel educativo, así como de las condiciones propias de los procesos de descentralización de cada CCAA que se han presenta de manera detallada en otros estudios desarrollados por el autor.

\section{2.- Determinantes en la asignación de los recursos para las universidades}

La asignación de los recursos monetarios en las casas de estudios superiores está supeditada a elementos de entrada (inputs) y de salida (outputs) que tienen dichas instituciones. De acuerdo a Cañabate \& Cuervo (1996), los elementos basados en inputs están referidos a alumnos, profesorado, estudiantes a tiempo completo, entre otros.

Los criterios basados en outputs, de acuerdo a los referidos autores, consideran los resultados o productos generados por esas instituciones y toma como variables a los titulados, créditos aprobados, tasas de empleo, etc. Cuando se toman en cuenta "sistemas mixtos", se hace una combinación de ambos tipos de variables. 
De los recursos financieros que disponen las universidades, si bien son los públicos los que tradicionalmente han tenido mayor importancia y volumen, también son los que de alguna manera presentan mayor problema por su escasez para los Estados. Es por ello que la diversidad e innovación de ingresos que pueda proceder de entes privados hace que los mismos, cada vez vayan teniendo mayor participación y aceptación en los distintos centros educativos de enseñanza superior.

Lo antes referido de acuerdo a Gabriel Ramírez Torres (2007) está fundamentado en que:

"Las universidades, en pro de mantener su rol como centros de estudios autónomos, deben procurar diversificar los recursos, captar fondos y aplicar distintas estrategias para involucrar a sus contribuyentes en su tarea y de esa manera garantizar su permanencia y desarrollo en el tiempo, es decir, en términos de las nuevas corrientes de desarrollo, ser Sustentable”. Pág. 56

A su vez, en el informe "Financiación y Gestión de las Universidades", realizado por un equipo coordinado por María Jesús San Segundo, se señala que la combinación adecuada de la manera de financiación universitaria depende de los resultados que los diferentes instrumentos tengan sobre algunos objetivos del financiamiento de las universidades, como lo es el caso de suficiencia financiera para garantizar que las universidades dispongan de los recursos necesarios para realizar sus funciones, así como por la eficiencia externa en la asignación de recursos de la sociedad a las universidades y su reparto entre ellas.

\section{3.- Estructura del financiamiento de las universidades públicas españolas}

Si partimos de la base de que si bien es el Estado quien debe garantizar los fondos que cubran buena parte del costo del servicio educativo, - sobre todo en las etapas de la educación obligatoria -, es también éste quien en la medida en que se vaya ascendiendo dentro de los distintos niveles educativos, debería estimular a las universidades para que puedan generar otras vías de financiación que de alguna manera, también les permita profundizar no sólo su autonomía académica y administrativa, sino también financiera.

En tal sentido, podríamos hacer el símil del Estado, como los padres, y las universidades como sus hijos o hijas. Para expresarlo en pocas palabras diremos que todo padre debe ser más cuidadoso y protector con sus hijos en los primeros años, debe ayudarlos a que se desarrollen y que éstos lleguen a ser independientes en un momento dado, en la medida en que ellos vayan creciendo. Es decir, el Estado debe fomentar el crecimiento en todos los niveles de sus universidades con el fin de que éstas se hagan más independientes. Lo anterior no implica que se dé una ruptura entre ambos individuos, todo lo contrario, aun cuando los hijos ya estén formados los padres continúan estando pendiente de ellos y viceversa. Debería ocurrir lo mismo en la relación Estado-Universidades.

No obstante lo antes referido, en la publicación "La financiación de las universidades públicas en España a inicios del Siglo XXI. De las Tercias a las Titulizaciones” de Gabriel Ramírez Torres (2007), ya se hacía refe- 
rencia a una situación de crisis que podría abrir el camino a una diversificación del sistema de financiamiento de las universidades. En dicha publicación se afirmaba:

Muchos países están considerando la inclusión de la participación de otros agentes distintos a los tradicionales, como forma de captación de recursos para financiar la educación, sin que ello represente una menor participación de las funciones del Estado en esa materia. Pág. 59.

A continuación se presentan los mecanismos de cómo pueden las universidades generar recursos para su financiación, pasando desde los esquemas tradicionales de las asignaciones o aportes que realicen el Estado (mediante fondos públicos) y los estudiantes (matrículas y pagos de otras tasas), hasta mecanismos más innovadores que implican el uso de prácticas de gerencia como lo es obtener recursos a través del mercado de valores.

El denominador común de todas las casas de estudios superiores españolas en términos de sus ingresos contempla una serie de siete partidas que se presentan de manera genérica en el cuadro $\mathrm{N}^{\circ} 2$, así como los conceptos más relevantes que conforman a cada uno de los ingresos en el caso español.

Cuadro $N^{\circ}$ 2: Tipos de ingresos obtenidos por las universidades públicas españolas

\begin{tabular}{|c|l|l|}
\hline \multicolumn{1}{|c|}{ Ingresos } & \multicolumn{1}{|c|}{ Característica } & \multicolumn{1}{|c|}{ Aportaciones obtenidas } \\
\hline Capítulo III & $\begin{array}{l}\text { Ingresos referidos fundamentalmente por el } \\
\text { pago de matrículas, precios públicos. } \\
\text { Servicios académicos. }\end{array}$ & $\begin{array}{l}\text { Tasas públicas. } \\
\text { Matrículas y pagos por distintas razones realizadas } \\
\text { por los estudiantes. }\end{array}$ \\
\hline Capítulo IV & $\begin{array}{l}\text { Ingresos referidos fundamentalmente por trans- } \\
\text { ferencias de las CCAA y otros entes públicos. }\end{array}$ & $\begin{array}{l}\text { Presupuestos sum lump. } \\
\text { Subvención incremetalista. } \\
\text { Fórmulas de financiación. } \\
\text { Subvención a las plazas. } \\
\text { Contratos Programas. }\end{array}$ \\
\hline Capítulo V & $\begin{array}{l}\text { Ingresos referidos fundamentalmente por ingre- } \\
\text { sos patrimoniales, rentas, inversiones de las ca- } \\
\text { sas de estudios. }\end{array}$ & $\begin{array}{l}\text { Aportaciones directas e indirectas. } \\
\text { Parques tecnológicos. } \\
\text { Recursos provenientes de mecenazgos. }\end{array}$ \\
\hline Capítulo VI & $\begin{array}{l}\text { Ingresos referidos fundamentalmente por la ven- } \\
\text { ta de activos fijos de las universidades. }\end{array}$ & $\begin{array}{l}\text { Captación de recursos fundamentalmente prove- } \\
\text { nientes de donaciones y mecenazgos. }\end{array}$ \\
\hline Capítulo VII & $\begin{array}{l}\text { Ingresos referidos fundamentalmente para la in- } \\
\text { vestigación y desarrollo. }\end{array}$ & $\begin{array}{l}\text { Recursos provenientes de las distintas instancias pú- } \\
\text { blicas. } \\
\text { Desarrollo de centros y parques tecnológicos. } \\
\text { Aportaciones de organismos internacionales. }\end{array}$ \\
\hline Capítulo VIII & $\begin{array}{l}\text { Ingresos referidos fundamentalmente por la ven- } \\
\text { ta de activos financieros de las universidades. }\end{array}$ & Reintegro de préstamos, fianzas, etc. \\
\hline
\end{tabular}


Fuente: Elaboración propia.

\subsection{Cronología de la crisis española entre 2008-2012}

La economía española experimentó un crecimiento importante en el siglo XX, a pesar de haber transitados por una situación que la sumió en una guerra civil (1936-1939) que conllevó al establecimiento, posteriormente a ésta, a un período de dictadura bajo la presidencia de Francisco Franco por más de tres décadas.

El crecimiento experimentado en España desde los años de la transición a la democracia fue de mucha relevancia en sus inicios, pero de gran impacto en la medida que este país se adentró en el proceso de integración europea llevada a cabo a mediados de los años ochenta del siglo pasado.

Con la transición e instauración de la democracia en España a partir de 1976, su crecimiento económico fue año tras año más importante, exceptuando un par de años particulares. Si bien la diversificación industrial se fue evidenciando, el turismo tuvo por muchos años un peso importante en el PIB del país de cuerdo a Brida, Pereyra y Such (2008).

En las ilustraciones $\mathrm{N}^{\circ} 1$, se presentan los aspectos más relevantes de la situación que muestran el impacto de la crisis económica vivida en España a partir del 2007 hasta el 2009, de acuerdo a posiciones planteadas por distintos autores, organizaciones y medios de comunicación que han registrado lo vivido en ese país en el período referido, denominados de la burbuja inmobiliaria al reconocimiento de la crisis.

Ilustración $\mathrm{N}^{\circ}$ 1: Cronología de la crisis económica reciente en España.

\begin{tabular}{|c|c|c|}
\hline $\begin{array}{c}1998 \text { - } 2007 \\
\text { Generación burbuja inmobiliaria }\end{array}$ & $\begin{array}{c}2008 \\
\text { Conocimiento de la crisis }\end{array}$ & $\begin{array}{c}2009 \\
\text { Reconocimiento de la crisis }\end{array}$ \\
\hline $\begin{array}{l}\text { - Entre } 1998 \text { y } 2007 \text { la costruccción } \\
\text { aportó más del } 20 \% \text { del PIB. } \\
\text { - Porción del PIB en inversión resi- } \\
\text { dencial pasó de } 5 \% \text { en los } 90 \text { a un } \\
7,4 \% \text { en el } 2007 . \\
\text { - Cuarta economía de Europa y oc- } \\
\text { tava a nivel mundial. }\end{array}$ & $\begin{array}{l}\text { - Aprobación de } € 10.000 \mathrm{MM} \\
\text { para activar la economía. } \\
\text { - Crecimiento del PIB sólo del } \\
1,2 \% \text {. } \\
\text { - No se habla de crisis, sino de } \\
\text { desaceleración económica. } \\
\text { - Cobertura pra el Fondo de Ga- } \\
\text { rantía de Depósitos hasta por } \\
€ 100.000 \text {. }\end{array}$ & $\begin{array}{l}\text { - Bajada de la calificación crediticia. } \\
\text { IPC negativo en } 0,1 \% \text { (por primera vez en Es- } \\
\text { paña). } \\
\text { - Reducción del impuesto a la Renta de Per- } \\
\text { sonas Físicas por adquisisción de viviendas. } \\
\text { - Medidas de incentivo al sector automovilís- } \\
\text { tico. } \\
\text { - Restructuración del sector financiero, me- } \\
\text { diante fusiones de Cajas de Ahorro. } \\
\text { - PIB cayó } 3.8 \% \text {. } \\
\text { - Tasa de desempleo en } 18.83 \%\end{array}$ \\
\hline
\end{tabular}

Fuente: Elaboración Propia a partir de consulta a distintos autores e instituciones y medios de comunicación. 
Por su parte, en la ilustración $\mathrm{N}^{\circ} 2$, se presenta la situación vivida en España entre 2010 y 2012, denominadas ¿Concientización de la crisis? Hasta el último año denominado y sigue la persiana "Blackout" abajo.

Ilustración $\mathrm{N}^{\circ}$ 2: Cronología de la crisis económica reciente en España.

\begin{tabular}{|c|c|c|}
\hline ¿Concienciación de la crisis? & $\begin{array}{l}2011 \\
\text {...y continúa la Recesión! } \\
\text { Era Black Cards } \\
\end{array}$ & $\begin{array}{c}2012-2013 \\
\text {...y sigue la Blackout abajo! }\end{array}$ \\
\hline $\begin{array}{l}\text { - La bolsa española perdió un } \\
5,94 \% \text {. } \\
\text { - Declaraciones de la UE y el } \\
\text { FMI acerca del riesgo de España } \\
\text { dentro de la zona del euro. } \\
\text { - La tasa de paro supera el } 20 \% \text {. } \\
\text { - Grupo de bancos fueron inter- } \\
\text { venidos. } \\
\text { - Subida del IVA en un } 2 \% \text {. } \\
\text { - Se permitió la inversión priva- } \\
\text { da en cajas de ahorros. } \\
\text { - Se cerró con un déficit de } 9,24 \%\end{array}$ & $\begin{array}{l}\text { - Reforma de pensiones. } \\
\text { - Continuacion de la reestructuración del } \\
\text { sector finanaciero. } \\
\text { - La prima de resgo alcanza el nivel más } \\
\text { alto desde que España ingresara a la UE } \\
\text { (398,3 pb). } \\
\text { - Se aprobó enmienda constitucional para } \\
\text { que los futuros goiernos mantegan el equi- } \\
\text { librio presupuestario en tiempos de creci- } \\
\text { miento económico. } \\
\text { - Paro alcanza } 215 \% \text {. } \\
\text { - Moody's bajó la calificación de la deuda a } \\
\text { largo plazo de diez CCAA. }\end{array}$ & $\begin{array}{l}\text { - Stanford \& Poor disminuyen la cali- } \\
\text { ficación de la deuda a BBB+. } \\
\text { - Se nacionaliza BANKIA la cuarta } \\
\text { entidad dinancieras más importante } \\
\text { del país. } \\
\text { - Se toman medidas orientadas a cum- } \\
\text { plir con imposiciones europeas para } \\
\text { salir de la crisis como: rebaja tanto } \\
\text { de sueldos de los empleados públicos } \\
\text { como su número. } \\
\text { - Decrecimiento de la economía. } \\
\text { - Deuda pública alcanza el } 94 \% \text { del } \\
\text { PIB. }\end{array}$ \\
\hline
\end{tabular}

Fuente; Elaboración Propia a partir de consulta a distintos autores e instituciones y medios de comunicación.

\section{3.- ¿Crisis en la financiación de las universidades españolas?}

A pesar de la evidente situación de crisis económica vivida en España en los últimos años referidos, en esta sección, se procede a explicar de manera general la forma cómo las universidades públicas españolas se han financiado, sus relaciones y la participación estudiantil dentro de la financiación de dichas Instituciones tanto unos años antes de la crisis, como posteriores al reconocimiento de dicha situación y verificar si más que en montos absolutos ha habido un cambio en el financiamiento de esas instituciones.

\section{1.- $\quad$ Situación de la financiación de las universidades españolas antes y después de la crisis}

Los Estados mantienen relaciones con sus instituciones de educación superior que están dadas fundamentalmente por el marco legal que las rige y en el caso de la financiación de las universidades públicas españolas se ha referido anteriormente.

Esas casas de estudio en España están incluidas como parte de la administración descentralizada y consideradas en algunos casos como corporaciones públicas en materia de Presupuesto. No obstante, la mayoría de esas 
instituciones en materia de investigación y enseñanza tienen libertad de auto-administración y auto-gerencia, es decir, cuentan con autonomía académica, de acuerdo a Gabriel Ramirez Torres (2007).

Las instituciones de educación superior españolas, al pertenecer a entidades descentralizadas, tienen que sus presupuestos forman parte de las cuentas de cada Comunidad Autónoma, siendo las mismas aprobadas por sus respectivas Juntas de Gobiernos. A su vez, dichas instituciones están sometidas a la supervisión Estatal, por parte del Ministerios de Educación, Cultura y Deporte, así como a un control legal de las respectivas instancias en las Direcciones Generales de Universidades para el caso de la mayoría de las comunidades autónomas.

Las responsabilidades estatales en las instituciones de educación superior españolas pueden ser descritas como un conjunto de condiciones establecidas por sus respectivas CCAA en un marco legal, que les otorga a las mismas los recursos necesarios para su financiamiento, a la vez que les provee de infraestructuras adecuadas para realizar sus funciones.

Una parte importante del financiamiento de la educación superior en España es dotado por recursos públicos. Las universidades al formar parte de las CCAA, sus gastos corrientes de enseñanza y de investigación (salarios, materiales y costos operativos), se financian a través de los presupuestos de las mismas en un alto porcentaje ${ }^{1}$.

Las instituciones de educación superior obtienen sus recursos por diversas fuentes, en el caso de las universidades españolas los principales ingresos provienen del Capítulo 3 “Tasas, Precios Públicos y Otros”, en los que se encuentran las matrículas que pagan los estudiantes, así como de las Transferencias Corrientes - Capítulo 4 - que comprende los recursos que destinan las comunidades autónomas a las distintas casas de estudios como se presenta en Gabriel Ramírez Torres (2007).

Por otra parte, se tiene que de acuerdo a un informe publicado en el mes de marzo de 2014 por la Comisión de Enseñanzas del sindicato Comisiones Obreras, CCOO, (2009), se señala que los presupuestos de las universidades públicas españolas ha ido disminuyendo básicamente desde el año 2009, siendo más fuerte su caída a partir del año 2013. En dicho informe, se plantea que:

"La inversión en educación superior entre los años 2009 y 2013 ha disminuido más de $€ 1.226$ millones de euros, que supone un 12,32 \% menos de financiación que en 2009 para el conjunto de universidades. Teniendo en

1 Uno de los logros alcanzados por las instituciones de educación superior en España es la administración descentralizada. El rol que juegan las CCAA es mucho más relevante que el del Gobierno Central. De hecho, para el año 2004, según cifras obtenidas en la página web del Ministerio de Educación y Ciencia, del total de los ingresos de las instituciones de educación superior, un $90 \%$ proceden aproximadamente de los gobiernos regionales, mientras que un 8,6\% del gobierno central y un 1,4\% de los municipales. Detalle de esta información se tiene en la página de su Ministerio de Educación. 
cuenta la evolución del IPC entre diciembre de 2008 y el mismo mes de 2013 (9,6\%), el porcentaje de pérdida se incrementa hasta 21,92\%”. Pp. 11 .

Si bien es cierto que de acuerdo a lo desarrollado en el informe se evidencia una disminución de los presupuestos para ese período de estudio, en términos absolutos, el porcentaje de disminución de los mismos en sí ya considera la porción de la pérdida del poder adquisitivo, por lo que volverlo a sumar, sería doble contabilizar ese efecto en la reducción de los presupuestos de las universidades públicas españolas.

Asimismo, el informe elaborado por la referida federación de enseñanzas del 2014 señala que los presupuestos han disminuido, a la vez, que los aportes que realizan los estudiantes por concepto de "tasas públicas", referido al Capítulo III de los ingresos de las universidades entre el 2009 y el 2013 han aumentado, dado que dichos aportes pasaron del 15,96\% en el 2009 al $21,81 \%$ en el 2013.

Si bien se ha evidenciado ese incremento en las tasas públicas en el período analizado, hay que considerar que desde inicios de los años 2000 los aportes que han realizado los estudiantes a las universidades por concepto de matrículas y otros pagos relacionados a sus estudios ha sido en promedio el $20 \%$ como se presenta en Gabriel Ramírez Torres (2007).

Ese planteamiento realizado por la federación de enseñanzas de CCOO, pareciera tener un doble sentido, por lo que el mismo sería más político que técnico. Es por ello, que se procederá a realizar un análisis o evaluación de si efectivamente ha habido un cambio significativo en el financiamiento de las universidades públicas españolas en los últimos años

\section{2.- Determinantes del financiamiento de las universidades antes y después de la crisis}

Para evaluar dicha situación, se realizará un análisis de regresión múltiple por medio del método de los mínimos cuadrados para determinar las variables que son significativas en el análisis.

Dentro de las variables a ser analizadas en el referido modelo se consideró como variable dependiente el presupuesto de las universidades públicas de las comunidades autónomas para el año 2013, mientras que las variables independientes se consideraron el presupuesto de esas casas de estudios para el año 2012, el PIB del 2012 y la cantidad de alumnos matriculados para el referido año en esas instituciones.

Los resultados generados de la aplicación del modelo de regresión se presentan en el cuadro $\mathrm{N}^{\circ} 3$, en donde se tiene que las variables presupuesto del año anterior (X1), PIB de las CCAA (X2) y cantidad de estudiantes (X3) explican de una manera directa en un $99 \%$ a la variable dependiente, denominada presupuesto del 2013 (Y). El restante $1 \%$ se debe al error de estimación o a otros factores distintos no considerados en el modelo. 


\begin{tabular}{|l|r|}
\hline \multicolumn{2}{|c|}{ Regression Statics } \\
\hline Multiple R & 0,998449908 \\
\hline R Square & 0,996902219 \\
\hline Adjusted R Square & 0,996187347 \\
\hline Standar Error & 32980272,07 \\
\hline Observations & 17 \\
\hline
\end{tabular}

\begin{tabular}{|l|r|r|r|r|r|}
\hline \multicolumn{7}{|c|}{ ANOVA } \\
\hline & $d f$ & $S S$ & $M S$ & $F$ & Significance $F$ \\
\hline Regression & 3 & $4,55044 \mathrm{E}+18$ & $1,51681 \mathrm{E}+18$ & 1394,517651 & $1,49279 \mathrm{E}-16$ \\
\hline Residual & 13 & $1,41401 \mathrm{E}+16$ & $1,0877 \mathrm{E}+15$ & & \\
\hline Total & 16 & $4,56458 \mathrm{E}+18$ & & & \\
\hline
\end{tabular}

\begin{tabular}{|l|r|r|r|r|r|r|}
\hline & \multicolumn{1}{|c|}{ Coefficients } & Standard Error & \multicolumn{1}{c|}{ t Stat } & \multicolumn{1}{c|}{ P-value } & \multicolumn{1}{|c|}{ Lower 95\% } & \multicolumn{1}{l|}{ Upper 95\% } \\
\hline Intercept & $-4822880,435$ & 12208416,29 & $-0,395045542$ & 0,699214881 & $-31197560,28$ & 21551799,41 \\
\hline X Variable 1 & 0,997435641 & 0,057416653 & 17,37188746 & $2,2898 \mathrm{E}-10$ & 0,873394503 & 1,121476779 \\
\hline X Variable 2 & 0,000994635 & 0,000440346 & 2,258755613 & 0,041727087 & $4,33243 \mathrm{E}-05$ & 0,001945945 \\
\hline X Variable 3 & $-1065,229134$ & 214,5239641 & $-4,965548435$ & 0,000258222 & $-1528,679982$ & $-601,7782871$ \\
\hline
\end{tabular}

Fuente: Cálculos Propios.

De los coeficientes de la ecuación se tiene, por ejemplo que el correspondiente a X1 presupuesto del año 2012, indica que si el resto de variables se mantienen constantes, a un aumento de un euro en el presupuesto del 2012, le corresponde en promedio un aumento de 0,997 euros en el presupuesto del 2013.

Similar situación se tendría para el caso de X2 definida como PIB, señalando que si se mantienen las demás variables constantes, un aumento de un euro en el PIB de cada región, se destinará un 0,000995 euro al presupuesto de las universidades.

Asimismo, se tiene que analizando las correlaciones entre las distintas variables entre sí (ver cuadro $\mathrm{N}^{\circ} 4$ ), todas estas variables tienen una alta relación y explicación entre ellas, por lo que se pueden considerar todas las variables como significativas en la explicación del presupuesto. 
Cuadro $\mathrm{N}^{\circ}$ 4: Tabla de correlaciones de las distintas variables del modelo

\begin{tabular}{|l|r|r|r|}
\hline & \multicolumn{1}{|c|}{ X1 } & \multicolumn{1}{|c|}{ X2 } & \multicolumn{1}{c|}{ X3 } \\
\hline X1 & 1 & & \\
\hline X2 & 0,94752 & 1 & \\
\hline X3 & 0,94494 & 0,9011 & 1 \\
\hline
\end{tabular}

Fuente: Cálculos Propios.

Como se puede observar, las variables que son significativas de acuerdo a la distribución t del modelo de regresión, es decir, de las que si depende la variable presupuesto de las universidades públicas son los ingresos presupuestados del año 2012, el PIB y el número de estudiantes matriculados de ese mismo año, por lo que serán esas variables las que serán utilizadas posteriormente para realizar contrastes o pruebas de hipótesis y verificar si ha habido algún cambio en lo planteado.

Asímismo, se procede a realizar un análisis comparativo del financiamiento destinado por las distintas comunidades autónomas a sus casas de estudios públicas.

Este tipo de evaluación es muy común en las investigaciones de las ciencias sociales, humanísticas y educativas, dado que se suele recurrir a la aplicación de la técnica de comparación para analizar el objeto de estudio establecido dentro de su contexto, así como con otras realidades. Este tipo de análisis por su parte, está configurado como señala Ferrán Ferrer (1990) en cuatro variables como lo son el sujeto, el área, la naturaleza y el sentido de la comparación como lo señala Ferrer, F. (1990).

La variable sujeto de la comparación en esta investigación se trata del financiamiento de las universidades públicas, que dado que la variable significativa son los ingresos obtenidos por las casas de estudios, así como el PIB de esas comunidades. En cuanto al área la comparación se realiza entre las distintas comunidades autónomas de España.

En relación con la naturaleza de la comparación se tiene por un lado que se hace una comparación descriptiva del financiamiento recibido por las universidades, tanto de las Comunidades Autónomas, como de los otros ingresos recibidos.

El sentido de la comparación empleada es tanto estática, por tomar en cuenta las realidades en un momento determinado para cada año considerado en sí (análisis vertical), en cuanto dinámica por la consideración de situaciones en evolución, es decir para su comparación en distintos momentos (análisis horizontal).

El uso de dicha técnica en este trabajo se realiza, basado en el hecho de que parte de la información que se compara en los modelos es numérica, por lo que su aplicación puede ayudar al análisis de una manera concreta. 
En el caso del análisis vertical, se parte de la consideración de los recursos destinados por las 17 comunidades autónomas para un año en particular a las 50 casas de estudios que funcionan en todo el país ${ }^{2}$.

En el cuadro $\mathrm{N}^{\circ} 5$ se presenta el total de recursos destinados por cada comunidad autónoma a las universidades públicas de esa región, la participación de cada CCAA dentro del total, así como una evolución del presupuesto que se ha consignado a las distintas casas de estudios para esas comunidades en distintos momentos históricos.

Cuadro $\mathrm{N}^{\circ}$ 5: Evolución presupuestaria de las universidades públicas españolas

\begin{tabular}{|c|c|c|c|c|c|c|c|c|}
\hline \multirow[b]{2}{*}{ Comunidad } & \multicolumn{8}{|c|}{ Evolución del presupuesto de las universidades públicas españolas } \\
\hline & 2012 & $\begin{array}{l}\text { Intra } \\
2012\end{array}$ & $\begin{array}{c}\text { Var. } \\
2012 / 2008\end{array}$ & 2008 & $\begin{array}{l}\text { Intra } \\
2008\end{array}$ & $\begin{array}{c}\text { Var. } \\
2008 / 2004\end{array}$ & 2004 & $\begin{array}{l}\text { Intra } \\
2004\end{array}$ \\
\hline Andalucía & $1.780 .936 .890,16$ & $19 \%$ & $-0,08$ & 1.923.350.920,37 & $19 \%$ & 0,34 & $1.273 .748 .918,13$ & $16 \%$ \\
\hline Aragón & $255.965 .686,00$ & $3 \%$ & $-0,15$ & $293.744 .709,00$ & $3 \%$ & 0,30 & $206.077 .191,00$ & $3 \%$ \\
\hline Asturias & $211.502 .750,00$ & $2 \%$ & 0,02 & $208.300 .053,52$ & $2 \%$ & 0,19 & $169.309 .606,29$ & $2 \%$ \\
\hline Cantabria & $123.905 .707,00$ & $1 \%$ & $-0,05$ & $130.120 .873,80$ & $1 \%$ & 0,37 & $82.105 .065,74$ & $1 \%$ \\
\hline Castilla y León & $527.363 .093,00$ & $6 \%$ & $-0,04$ & $548.351 .140,72$ & $5 \%$ & 0,18 & $449.550 .992,82$ & $6 \%$ \\
\hline Castilla La Mancha & $171.650 .339,00$ & $2 \%$ & $-0,34$ & $229.873 .749,04$ & $2 \%$ & 0,15 & 195.262.397,98 & $2 \%$ \\
\hline Cataluña & $1.325 .314 .313,80$ & $14 \%$ & $-0,16$ & 1.538.124.419,00 & $15 \%$ & $-0,19$ & 1.825.167.239,57 & $22 \%$ \\
\hline Comunidad Valenciana & $1.075 .325 .239,26$ & $12 \%$ & $-0,18$ & 1.268.968.441,10 & $12 \%$ & 0,27 & $921.730 .676,25$ & $11 \%$ \\
\hline Extremadura & $138.915 .917,00$ & $2 \%$ & $-0,15$ & $159.993 .730,20$ & $2 \%$ & 0,40 & $96.528 .646,71$ & $1 \%$ \\
\hline Galicia & $500.648 .491,12$ & $5 \%$ & $-0,21$ & $607.910 .942,20$ & $6 \%$ & 0,28 & $438.437 .552,77$ & $5 \%$ \\
\hline Islas Baleares & $88.221 .578,30$ & $1 \%$ & $-0,47$ & $129.284 .470,55$ & $1 \%$ & 0,47 & $68.687 .503,09$ & $1 \%$ \\
\hline Islas Canarias & $296.505 .093,00$ & $3 \%$ & $-0,08$ & $321.030 .236,52$ & $3 \%$ & 0,15 & $273.644 .335,72$ & $3 \%$ \\
\hline Madrid & $1.863 .830 .149,85$ & $20 \%$ & $-0,08$ & 2.004.865.697,20 & $19 \%$ & 0,24 & $1.521 .426 .956,33$ & $19 \%$ \\
\hline Murcia & $240.985 .970,11$ & $3 \%$ & $-0,20$ & $288.382 .142,99$ & $3 \%$ & 0,34 & $191.456 .956,33$ & $2 \%$ \\
\hline Navarra & $70.591 .528,14$ & $1 \%$ & $-0,24$ & $87.416 .651,65$ & $1 \%$ & 0,25 & $65.619 .084,84$ & $1 \%$ \\
\hline País Vasco & $441.331 .563,00$ & $5 \%$ & $-0,25$ & $549.508 .678,00$ & $5 \%$ & 0,40 & $329.231 .332,91$ & $4 \%$ \\
\hline La Rioja & $42.855 .499,91$ & $0 \%$ & 0,00 & $42.700 .021,43$ & $0 \%$ & 0,20 & $34.066 .452,53$ & $0 \%$ \\
\hline TOTAL & $9.115849 .808,65$ & & $-0,13$ & $10.331 .926 .877,29$ & & 0,21 & $8.142 .050 .885,20$ & \\
\hline
\end{tabular}

Fuente: Elaboración propia partiendo de la suma de los presupuestos de las universidades públicas de cada comunidad autónoma para cada año.

2 Como se hizo referencia en el capítulo III de este trabajo, se están considerando las universidades que dependen directamente de cada comunidad autónoma, dejando por fuera el caso de la Universidad de Estudios a Distancias UNED, que por sus características y estructura depende del MECD. 
Para el año 2004 se destinaron $€ 8.142 .050 .885,20$ a la totalidad de las cincuenta universidades de las 17 comunidades autónomas, por lo que se puede decir que el grupo de las siete universidades catalanas, que recibieron $€ 1$ 1.825.167.239,57 fueron las que obtuvieron mayores recursos, que a su vez representan aproximadamente el $22 \%$ del total de lo percibido por todas las universidades españolas, seguidas de las universidades de la Comunidad de Madrid y de Andalucía con un $19 \%$ y $16 \%$ respectivamente.

Asimismo, se evidencia en el referido cuadro que las universidades de las comunidades de Cantabria, Extremadura, Islas Baleares, Floral de Navarra y La Rioja recibieron, aproximadamente, $1 \%$ o menos del total de los recursos destinados a las casas de estudios españolas.

Para el año 2008, las universidades públicas de las comunidades de Andalucía y Madrid son las que reciben mayores cantidades de recursos con $19 \%$ cada una, seguidas de las universidades catalanas y valencianas con un $15 \%$ y $12 \%$ respectivamente. Los recursos destinados al resto de instituciones de educación superior se encuentran entre aproximadamente $1 \%$ y $6 \%$ del total de los recursos que conforman los ingresos de las universidades públicas españolas.

En 2012 las universidades españolas que más recursos perciben fueron las de la Comunidad de Madrid, que recibieron en promedio el $20 \%$ de lo que recibieron todas las casas de estudios españolas en su conjunto, seguida por las comunidades de Andalucía, Cataluña y Valencia, mientras que Las universidades de las comunidades de Cantabria, Extremadura, Islas Baleares, Floral de Navarra y La Rioja fueron las que menos recursos recibieron.

El criterio que se utilizó para analizar el financiamiento de las universidades públicas españolas en tres momentos diferentes, es verificar la evolución del financiamiento de las universidades públicas cuatro años antes y después de la crisis económica vivida a nivel global, con repercusión importante en España. Es por ello, que se considera el año 2004, como período antes del año en que se puede considerar como de inflexión de la crisis mundial y en lo particular la española (2008), y otro período de cuatro años transcurridos al inicio de esa crisis, como lo es año 2012.

Del referido cuadro $\mathrm{N}^{\circ} 4$, teniendo en cuenta un análisis vertical de sus partidas, se tiene que del año 2004 al 2008 hubo un incremento de los ingresos que conformaron los presupuestos de las universidades públicas españolas, excepto en el caso de las universidades catalanas, que en promedio vieron disminuir sus ingresos en aproximadamente un $19 \%$ en ese período.

Las universidades públicas de comunidades como las de Islas Baleares, del País Vasco y Extremadura tuvieron un incremento en los ingresos de sus presupuestos superior al 40\% entre 2004 y 2008, lo que refleja que en ese período había un proceso de crecimiento económico en la mayoría comunidades autónomas de España, dado que son ellas, como ya se hizo referencia, las que otorgan en un amplio porcentaje el presupuesto de las casas de estudios públicas de esas comunidades.

El total de los recursos que constituyeron los ingresos de las universidades públicas españolas, cuyo monto fue de $€ 10.331 .926 .877,29$ para el año 2008, disminuyó a € 9.155.849.808,65 en el año 2012, lo que significa una reducción en términos absolutos de $€ 1$ 1.176.077.068,64. 
Por otra parte, si se considera la evolución de los recursos destinados a las universidades públicas de todas las comunidades autónomas entre los años 2008 al 2012, se tiene que para todas esas casas de estudios hubo una disminución promedio del presupuesto de aproximadamente $13 \%$, siendo las comunidades con mayor disminución presupuestarias en ese lapso las de Islas Baleares con una caída del 47\%; la de Castilla La Mancha bajó el $34 \%$ y del País Vasco que experimentó una pérdida de sus ingresos del $25 \%$.

Cabe resaltar que justamente, las universidades públicas de Castilla La Mancha e Isla Baleares tuvieron una disminución mayor entre 2012 con relación al 2008, que el incremento que tuvieron de sus ingresos entre los años 2004 y 2008.

No obstante, el caso particular de la universidad de Oviedo tuvo un incremento del $2 \%$ en sus ingresos presupuestarios y en el caso de la Universidad de la Rioja prácticamente no evidenció ninguna modificación significativa en ese período.

En el cuadro $\mathrm{N}^{\circ} 6$ se presenta la evolución del Producto Interno Bruto, PIB en términos corrientes, de cada comunidad autónoma para los períodos analizados en el estudio.

Considerando la información presentada en el cuadro anterior, se tiene que hubo un crecimiento de la economía española, dado que su PIB pasó de $€$ 838.077.952.000,00 en 2004 a $€ 1.084 .299 .709 .000,00$ en 2008, lo que refleja un incremento de $22,71 \%$.

Cuadro $\mathrm{N}^{\circ}$ 6: Evolución del PIB por CCAA

\begin{tabular}{|l|r|r|r|}
\hline \multirow{2}{*}{ Comunidad } & \multicolumn{3}{|c|}{ Evolución del PIB por CCAA } \\
\cline { 2 - 4 } & PIB 2012 & \multicolumn{1}{c|}{ PIB 2008 } & PIB 2004 \\
\hline Andalucía & $138.922 .673 .000,00$ & $148.915 .411 .000,00$ & $115.477 .968 .000,00$ \\
\hline Aragón & $35.542 .862 .000,00$ & $34.071 .768 .000,00$ & $25.957 .386 .000,00$ \\
\hline Asturias & $21.888 .645 .000,00$ & $23.736 .703 .000,00$ & $18.002 .404 .000,00$ \\
\hline Cantabria & $12.537 .886 .000,00$ & $13.888 .906 .000,00$ & $10.491 .466 .000,00$ \\
\hline Castilla y León & $54.291 .495 .000,00$ & $58.128 .174 .000,00$ & $45.622 .278 .000,00$ \\
\hline Castilla La Mancha & $36.142 .609 .000,00$ & $36.857 .370 .000,00$ & $28.320 .087 .000,00$ \\
\hline Cataluña & $192.535 .185 .000,00$ & $202.695 .024 .000,00$ & $158.190 .971 .000,00$ \\
\hline Comunidad Valenciana & $97.622 .264 .000,00$ & $105.833 .509 .000,00$ & $81.873 .320 .000,00$ \\
\hline Extremadura & $16.367 .164 .000,00$ & $18.176 .031 .000,00$ & $13.958 .103 .000,00$ \\
\hline Galicia & $55.308 .264 .000,00$ & $56.220 .304 .000,00$ & $42.892 .048 .000,00$ \\
\hline Islas Baleares & $25.885 .857 .000,00$ & $27.196 .542 .000,00$ & $21.010 .728 .000,00$ \\
\hline Islas Canarias & $40.160 .786 .000,00$ & $42.907 .188 .000,00$ & $34.165 .867 .000,00$ \\
\hline Madrid & $185.187 .832 .000,00$ & $193.049 .514 .000,00$ & $148.809 .239 .000,00$ \\
\hline
\end{tabular}




\begin{tabular}{|l|r|r|r|}
\hline Murcia & $26.635 .779 .000,00$ & $28.164 .464 .000,00$ & $21.204 .570 .000,00$ \\
\hline Navarra & $17.764 .389 .000,00$ & $18.480 .722 .000,00$ & $14.266 .485 .000,00$ \\
\hline País Vasco & $63.597 .364 .000,00$ & $67.940 .865 .000,00$ & $51.610 .919 .000,00$ \\
\hline La Rioja & $7.846 .747 .000,00$ & $8.037 .214 .000,00$ & $6.224 .140 .000,00$ \\
\hline TOTAL & $\mathbf{1 . 0 2 5 . 2 3 7 . 6 9 1 . 0 0 0 , 0 0}$ & $\mathbf{1 . 0 8 4 . 2 9 9 . 7 0 9 . 0 0 0 , 0 0}$ & $\mathbf{8 3 8 . 0 7 7 . 9 5 2 . 0 0 0 , 0 0}$ \\
\hline
\end{tabular}

Fuente: Cifras obtenidas del PIB regional de las comunidades autónomas de acuerdo al INE

Si bien se generó un incremento en la totalidad de la economía de cada región, el mismo también tuvo un similar comportamiento en el total de recursos destinados a las universidades públicas españolas de todas las comunidades autónomas, debido a que dichos recursos también crecieron en promedio un 21,20\% para el período 2004 - 2008, en términos corrientes, al pasar de $€ 8.142 .050 .885,20 \mathrm{a} € 10.331 .926 .877,29^{3}$

Por su parte, dada la situación de crisis en España en el período referido, la economía de las distintas comunidades autónomas experimentó una contracción económica, evidenciada en la disminución de sus respectivos PIB del 2012 con relación al PIB de las CCAA para el año 2008.

De acuerdo a la información derivada de los dos cuadros anteriores, se tiene que si bien la disminución del PIB de las CCAA en el año 2012 con relación al 2008 fue del 5,58 \%, la deducción experimentada por los ingresos de las universidades españolas fue del $12,85 \%$ en el mismo período.

\section{3.- $\quad$ Pruebas al financiamiento de universidades públicas españolas}

Como se hizo referencia en el punto anterior, con la información presentada en los cuadros $\mathrm{N}^{\circ} 5$ y $\mathrm{N}^{\circ} 6$ y con el fin de verificar si ha habido una diferencia significativa en la asignación de los recursos obtenidos por las casas de estudios superiores españolas, se procede a realizar una prueba de hipótesis, partiendo de lo siguiente:

Hipótesis Nula (Ho): No hay diferencia significativa entre los montos de financiamiento de las universidades públicas de todas las comunidades autónomas españolas entre el año 2004 y el año 2008.

Hipótesis Alternativa (H1): hay una diferencia significativa en los ingresos de las universidades públicas españolas en dicho período.

En el cuadro $\mathrm{N}^{\circ} 7$ se presentan los resultados obtenidos de la aplicación de un contraste de hipótesis para la diferencia de medias muestrales, obtenido mediante la aplicación del paquete estadístico SPSS.

3 Información proveniente del cuadro $\mathrm{N}^{\circ} 4$. 
Dado que la suma de ambas muestras es un valor mayor a $30(17+17=34)$ se debe ajustar a una distribución Normal. Para ello se procede a calcular el Zteórico con un nivel de significación del $10 \%$ lo que da Zt $\alpha / 2=$ $\pm 1,64$.

Cuadro N 7: Diferencia de Medias para los años 2004 y 2008

\begin{tabular}{|l|r|r|}
\hline & AÑO 2008 & \multicolumn{1}{|c|}{ AÑ 2004 } \\
\hline Media en $€$ & $607.760 .404,55$ & $478.944 .169,72$ \\
\hline Desviación Estándar en $€$ & $653.126 .692,72$ & $557.234 .777,23$ \\
\hline Número CCAA & 17 & 17 \\
\hline Desviación Conjunta en $€$ & & $208.225 .708,09$ \\
\hline$Z$ Calculado & & 0,62 \\
\hline$Z$ Teórico con a $=\mathbf{1 0 \%}$ & & $-1,64$ \\
\hline
\end{tabular}

Fuente: Elaboración propia.

Establecimiento de las hipótesis:

Ho: $\mu 1-\mu 2=0 \quad$ H1: $\mu 1-\mu 2 \neq 0$

Una vez determinado el valor de Zc, se procede a comparar con el valor de $\mathrm{Zt} \alpha / 2$ y dado que $\mathrm{Z}$ t $\alpha / 2 \leq \mathrm{Zc} \leq$ $\mathrm{Zt} \alpha / 2$ se acepta la hipótesis nula de que no hay diferencia significativa entre los montos de financiamiento de la muestra de las universidades públicas españolas entre 2004 y 2008, con un nivel de significación del $10 \%$.

Asimismo, se procedió a realizar la prueba de hipótesis para verificar si hubo diferencia significativa en el financiamiento de las universidades públicas españolas entre 2008 y 2012, para ello se procedió a establecer lo siguiente:

Hipótesis Nula (Ho): No hay diferencia significativa entre los montos de financiamiento de las universidades públicas de todas las comunidades autónomas españolas entre el año 2008 y el año 2012.

Hipótesis Alternativa (H1): hay una diferencia significativa en los ingresos de las universidades públicas españolas en dicho período.

En el cuadro $N^{\circ} 8$ se presentan los resultados obtenidos de la aplicación de un contraste de hipótesis para la diferencia de medias muestrales para los años 2008 a 2012 de los ingresos de las universidades públicas españolas, con un nivel de significación del $10 \%$, obtenido mediante la aplicación del referido paquete estadístico 
Cuadro N 8: Diferencia de Medias para los años 2008 y 2012

\begin{tabular}{|l|r|r|}
\hline & AÑO 2008 & \multicolumn{1}{|c|}{ AÑO 2004 } \\
\hline Media en $€$ & $538.579 .400,51$ & $607.760 .404,55$ \\
\hline Desviación Estándar en $€$ & $596.118 .794,74$ & $653.126 .692,72$ \\
\hline Número CCAA & 17 & 17 \\
\hline Desviación Conjunta en $€$ & & $214.466 .793,56$ \\
\hline$Z$ Calculado & & 0,27 \\
\hline$Z$ Teórico con a $=\mathbf{1 0 \%}$ & & $-1,64$ \\
\hline
\end{tabular}

Fuente: Elaboración propia

Establecimiento de las hipótesis:

Ho: $\mu 1-\mu 2=0 \quad$ H1: $\mu 1-\mu 2 \neq 0$

Una vez determinado el valor de $\mathrm{Zc}$, se procede a comparar con el valor de $\mathrm{Z}$ t $\alpha / 2$ y dado que $\mathrm{Z} \mathrm{t} \alpha / 2 \leq \mathrm{Zc} \leq$ $\mathrm{Zt} \alpha / 2$ se acepta la hipótesis nula de que no hay diferencia significativa entre los montos de financiamiento de la muestra de las universidades públicas españolas entre 2008 y 2012 con un nivel de significación del $10 \%$. Cabe resaltar que igualmente se procedió a realizar el contraste de hipótesis para dichos períodos eliminando primero los montos extremos de los ingresos, es decir, dejando por fuera el monto más alto de los ingresos recibidos por una universidad española y el monto más bajo de los ingresos recibidos por una casa de estudios de ese país, con el fin de reducir el impacto de valores extremos.

Una vez realizado el ajuste referido en el párrafo anterior, se procedió a aplicar el mismo análisis para el agregado de las comunidades autónomas y se obtuvieron los resultados similares, por lo que se puede afirmar que no hay diferencia significativa entre los ingresos recibidos por las universidades públicas españolas entre 2004 y 2008 , así como tampoco hubo variación significativa de los ingresos de esas casas de estudios entre 2008 y 2012.

Otra de las variables a considerar en el análisis de si ha habido alguna variación importante en la asignación de los recursos a las universidades españolas por parte de sus respectivas CCAA es verificar la prueba de hipótesis tomando en cuenta si ha habido algún cambio en la porción que representa lo presupuestado para esas casas de estudio de sus respectivos PIB para los años analizados.

En el cuadro $N^{\circ} 9$ se presenta relación entre Presupuestos y PIB para cada año por CCAA, no obstante, dado que todos los contrastes dieron que no hubo diferencia significativa entre las relaciones consideradas, sólo se procederá a calcularlo entre el año 2012 y 2008. 
Cuadro $\mathrm{N}^{\circ}$ 9: Relación entre los presupuestos de las universidades de las CCAA y sus respectivos PIB por años.

\begin{tabular}{|l|r|r|r|}
\hline \multicolumn{1}{|c|}{ Comunidad } & \multicolumn{1}{c|}{ Ppto / PIB 2012 } & \multicolumn{1}{c|}{ Ppto / PIB 2008 } & \multicolumn{1}{c|}{ Ppto / PIB 2004 } \\
\hline Andalucía & 0,0128 & 0,0129 & 0,0110 \\
\hline Aragón & 0,0079 & 0,0086 & 0,0079 \\
\hline Asturias & 0,0097 & 0,0088 & 0,0094 \\
\hline Cantabria & 0,0099 & 0,0094 & 0,0078 \\
\hline Castilla y León & 0,0097 & 0,0094 & 0,0099 \\
\hline Castilla La Mancha & 0,0047 & 0,0062 & 0,0069 \\
\hline Cataluña & 0,0069 & 0,0076 & 0,0115 \\
\hline Comunidad Valenciana & 0,0110 & 0,0120 & 0,0113 \\
\hline Extremadura & 0,0085 & 0,0088 & 0,0069 \\
\hline Galicia & 0,0091 & 0,0108 & 0,0102 \\
\hline Islas Baleares & 0,0034 & 0,0048 & 0,0033 \\
\hline Islas Canarias & 0,0074 & 0,0075 & 0,0080 \\
\hline Madrid & 0,0101 & 0,0104 & 0,0102 \\
\hline Murcia & 0,0090 & 0,0102 & 0,0090 \\
\hline Navarra & 0,0040 & 0,0047 & 0,0046 \\
\hline País Vasco & 0,0069 & 0,0081 & 0,0064 \\
\hline La Rioja & 0,0055 & 0,0053 & 0,0055 \\
\hline
\end{tabular}

Fuente: Elaboración propia.

Hipótesis Nula (Ho): No hay diferencia significativa de las relaciones entre el presupuesto de las universidades públicas y el PIB de sus respectivas CCAA entre el año 2008 y el año 2012

Hipótesis Alternativa (H1): hay una diferencia significativa de las proporciones entre el presupuesto de las universidades públicas españolas y el PIB de sus CCAA en dicho período.

En el cuadro $\mathrm{N}^{\circ} 10$ se presentan los resultados obtenidos de la aplicación de un contraste de hipótesis para la diferencia de medias muestrales para los años 2008 a 2012 de las proporciones o relaciones señaladas con un nivel de significación del 10\%. 
Cuadro N 10: Diferencia de Medias de relación Presupuesto vs PIB entre 2012 y 2008

\begin{tabular}{|c|c|c|}
\hline & AÑO 2012 & AÑO 2008 \\
\hline Media en $€$ & 0,00802 & 0,00856 \\
\hline Desviación Estándar en $€$ & 0,00257 & 0,00238 \\
\hline Número CCAA & 17 & 17 \\
\hline Desviación Conjunta en $€$ & & 0,00085 \\
\hline Z Calculado & & $-0,63$ \\
\hline $\mathrm{Z}$ Teórico con $\mathrm{a}=10 \%$ & & $\pm 1,64$ \\
\hline
\end{tabular}

Fuente: Elaboración propia.

Establecimiento de las hipótesis:

Ho: $\mu 1-\mu 2=0 \quad$ H1: $\mu 1-\mu 2 \neq 0$

Una vez determinado el valor de $\mathrm{Zc}$, se procede a comparar con el valor de $\mathrm{Z}$ t $\alpha / 2$ y dado que $\mathrm{Zt} \alpha / 2 \leq \mathrm{Zc} \leq$ $\mathrm{Zt} \alpha / 2$ se acepta la hipótesis nula de que no hay diferencia significativa entre las proporciones entre los presupuestos de las universidades públicas y los PIB de cada región en España entre los años 2008 y 2012.

\section{4.- ¿Independencia política de los recursos asignados?}

Para analizar si existe una relación de independencia entre los montos destinados al financiamiento de las universidades de las distintas comunidades Autónomas y los partidos que dirigen dichas regiones, se procedió a realizar un análisis de varianza para cada uno de los años considerados en el estudios, a saber 2004; 2008 y 2012.

Cabe hacer referencia que en el análisis, se consideró la agrupación de las comunidades autónomas por el partido político gobernante para cada uno de los años previos al estudio, pues fueron los que aprobaron los presupuestos de las universidades para el siguiente ejercicio académico. A su vez, se consideró que en aquellas comunidades donde había alguna coalición para formar gobierno, se tomó en consideración la del partido político de mayor relevancia a nivel nacional, es por ello que se agruparon los resultados de los distintos años en las CCAA al Partido Popular (PP); Partido Socialista Obrero Español (PSOE) y Otros (que conforman el Partido Nacionalista Vasco (PNV), Coalición Canaria (CC) o Convergencia i Unio (CIU), entre otros).

En el cuadro $\mathrm{N}^{\circ} 11$ se presenta un resumen de la aplicación del análisis conocido como $\mathrm{F}$ de Snedecor para verificar si en los distintos momentos analizados ha habido un cambio significativo en los presupuestos de las universidades por la condición política de quienes dirigían sus respectivas comunidades autónomas en esos períodos. 


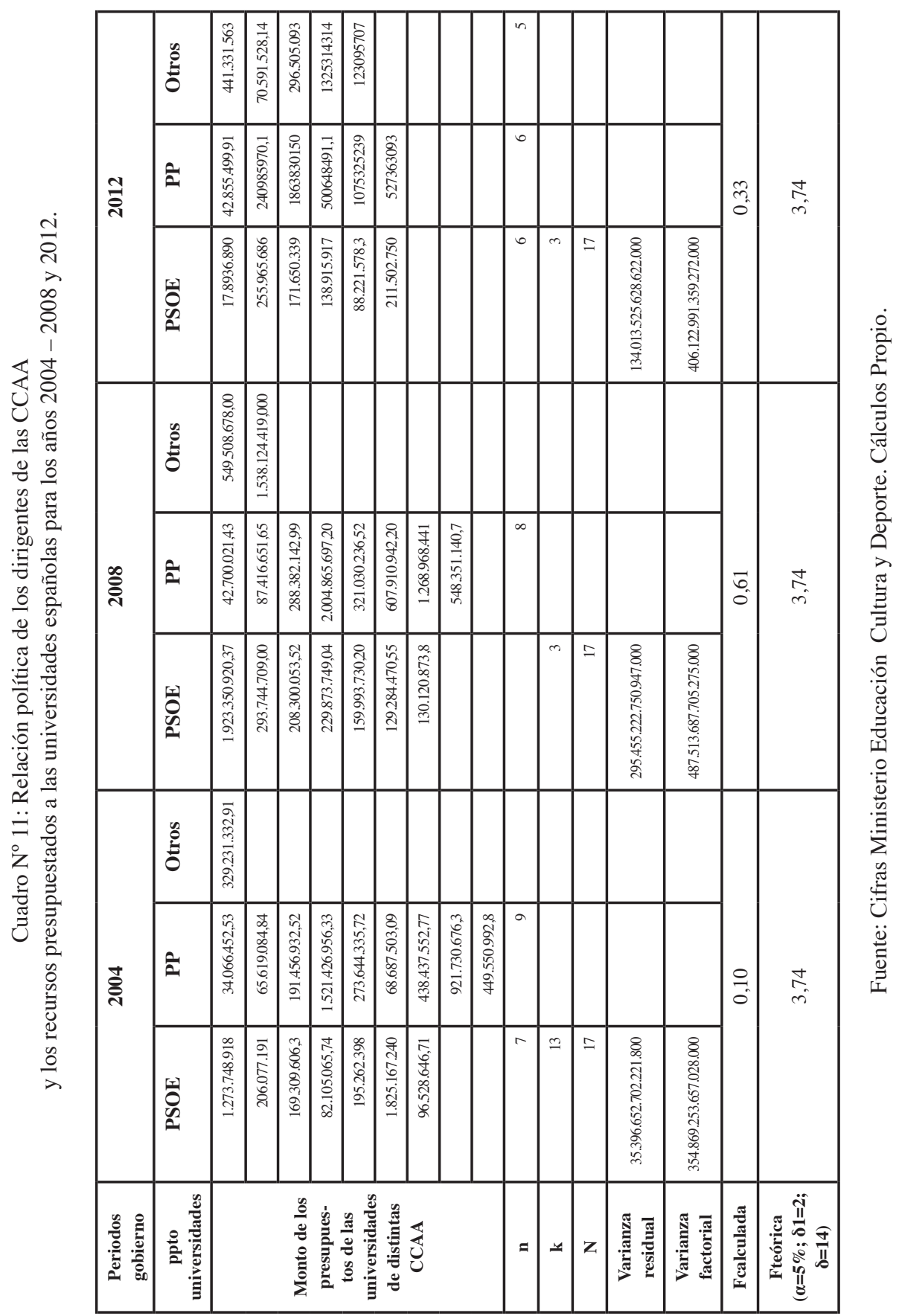


En cada uno de los años considerados, se parte de la Hipótesis Nula de que no hay diferencia entre el partido político que dirige una comunidad autónoma y la asignación de los presupuestos de las universidades públicas.

Por su parte, la Hipótesis Alternativa indica que si hay diferencia entre el partido político que dirige a las CCAA y la cantidad de recursos asignados a las instituciones de educación superior de esa región, con un nivel de significación del $5 \%$.

Una vez fijadas las hipótesis y obtenidos los valores calculados de la Distribución F, que se presentan en el cuadro $\mathrm{N}^{\circ} 10$, así como el valor de la Fteórico que es el mismo para todos los casos (considerando un nivel de significación del $5 \%$ y con 2 y 14 grados de libertad), se procede a comparar dichas situaciones y a tomar una decisión.

En tal sentido, se tiene que para el año 2004 el valor de $\mathrm{F}_{\text {calculado }}$ es de 0,10 mientras que el $\mathrm{F}_{\text {térico }}$ es de 3,74 . Dado que el valor $\mathrm{F}_{\text {calculado }}$ es menor que el valor del $\mathrm{F}_{\text {teórico }}$ se acepta la Hipótesis Nula, por lo que se puede afirmar que los presupuestos asignados a las universidades públicas españolas no varían dependiendo del partido político que gobierne esas comunidades autónomas.

Para el año 2008, como también se presenta en el cuadro antes referido, el valor de $\mathrm{F}_{\text {calculado }}$ es de 0,61 mientras que el $\mathrm{F}_{\text {térico }}$ es de 3,74. Dado que el valor $\mathrm{F}_{\text {calculado }}$ es menor que el valor del $\mathrm{F}_{\text {teórico }}$ se acepta la Hipótesis Nula, por la misma razón antes referida.

Ocurre también lo mismo para el año 2012, en el que el valor de Fcalculado es de 0,33 mientras que el $\mathrm{F}_{\text {teórico }}$ es de 3,74. Dado que el valor $\mathrm{F}_{\text {calculado }}$ es también menor que el valor del $\mathrm{F}_{\text {térico }}$ se acepta la Hipótesis Nula.

De lo antes desarrollado, se puede afirmar que derivado del análisis de varianza no hay una incidencia política al momento de la asignación de los presupuestos de las universidades públicas españolas, en ninguno de los tres momentos históricos estudiados, para las regiones, aún cuando hubo dos presidentes de gobiernos de distintos partidos, como Rodríguez Zapatero (2004-2011) y Mariano Rajoy (2011- actual).

\section{CONCLUSIONES}

Desde sus comienzos las instituciones de educación superior han tenido un impacto importante en el quehacer de las regiones donde se han creado, tanto en su desempeño vinculado a lo académico, como también en las relaciones con el mundo económico, social, político, científico que las rodea.

A pesar de la situación de crisis económica atravesada por España, la proporción de del PIB dentro del PIB total de sus comunidades autónomas se mantiene igual entre los años 2004; 2008 y 2012, es decir, Andalucía, Barcelona y Madrid, sólo por referirnos a unos, mantienen una porción del PIB total a lo largo del tiempo estudiado en $14 \%, 19 \%$ y $18 \%$ respectivamente. 
Las comunidades de Andalucía y Madrid han mantenido su proporción de recursos destinados a las universidades en relación a todos los recursos destinados a las universidades españolas, para cada uno de los años, siendo que en 2008 y 2012 la Comunidad de Madrid representa el $20 \%$ del total de los ingresos destinados a las universidades públicas. Andalucía por su parte, vio crecer su participación del total de recursos de las universidades públicas al incrementar esos recursos del 16\% del total en el año 2004 a $19 \%$ del total para el año 2012. El caso de la comunidad catalana ha sido distinto al de las otras dos comunidades referidas (sólo por citar las tres mas grandes), debido a que del $22 \%$ que representaba del total de los recursos en el año 2004, pasó a un $15 \%$ y $14 \%$ para los años 2008 y 2012 respectivamente.

Si se analiza la proporción que representa el presupuesto de las universidades públicas con relación al PIB de cada comunidad autónoma, se tiene que en promedio, no hay diferencias entre esas relaciones para los tres años analizados, en términos absolutos.

En cuanto a los ingresos por matrículas, tasas por pagos específicos ya sean de nuevos estudios, de estudios prolongados, etc., los estudiantes españoles pagaban en promedio cerca del $18 \%$ de dicho monto en el año 2004, mientras que en el año 2012 dicha cantidad alcanza aproximadamente el $20 \%$ el total de recursos percibidos por las universidades públicas españolas.

No obstante, se procedió a realizar pruebas de hipótesis para verificar si había diferencia significativa entre los presupuestos asignados a las universidades públicas españolas en los distintos momentos analizados y se concluyó que no hay diferencia significativa entre los montos de financiamiento de las universidades públicas españolas entre 2004 y 2008, así como entre los años 2008 y 2012, con un nivel de significación del $10 \%$.

Asimismo, de acuerdo a las pruebas realizadas se encontró que no hay diferencia significativa entre la diferencia de las medias muestrales de las proporciones de los presupuestos de las universidades públicas y los PIB de cada región en España para los años 2008 y 2012, así como para los períodos 2004 - 2008.

Cuando se analiza, a través del análisis de la Distribución F de Snedecor, si hay alguna incidencia entre los partidos políticos que administran las comunidades autónomas y los recursos asignados a las casas de estudios superiores de cada una de esas regiones, se encontró que para los años 2004; 2008 y 2012 sus respectivos valores de Fcalculado son menores que el valor del Fteórico, que con un nivel de significación del $5 \%$ se acepta la Hipótesis Nula, es decir, que se puede afirmar que los presupuestos asignados a las universidades públicas españolas no varían dependiendo del partido político que gobierne esas comunidades autónomas, al menos en los años considerados con el margen de error referido.

Dado lo antes referido, se puede decir que el planteamiento formulado por Comisiones Obreras en el documento titulado "Evolución de los presupuestos de las universidades públicas 2009 - 2013" de que ha habido una disminución significativa de los recursos asignados a las casas de estudios superiores por parte de las comunidades autónomas, es falso, por lo que hay más un componente político que técnico en las aseveraciones y 
conclusiones a que llegan en dicho documento.

Por otra parte, lo que si se debe señalar es que los recursos obtenidos por las universidades no son necesariamente los requeridos por las casas de estudios para operar adecuadamente, por lo que las universidades deberían preocuparse por obtener mayores recursos, por la vía de la diversificación de las fuentes de financiamiento.

Una alternativa que permitiría a las universidades obtener mayores ingresos, sin necesidad de aumentar los recursos obtenidos por el estado y sin trasladar a los estudiantes esos costos, podría ser la aplicación de Titulizaciones, para lo que las casas de estudios tendrían que lograr la posibilidad de emitir instrumentos financieros propios, con determinados tipos de activos. Para ello, habría que realizar modificaciones, en muchos casos, del Capítulo IX de la estructura del financiamiento de las universidades

Lo importante es las universidades no deben seguir financiándose de la forma tradicional en que lo han hecho en los últimos siglos - dependiendo en mayor parte de las asignaciones de los distintos niveles del Estado y de sus estudiantes -, sino abriendo espacios cada vez más a la participación de terceros y evaluando posibilidades innovadoras que puedan provenir del ámbito empresarial, sin desmejorarlas por su procedencia. 


\section{Bibliografía}

AGUSTİ, Colom.: La crisis económica española: orígenes y consecuencias. Una aproximación crítica. 2012. XIII Jornadas de Economía Crítica. Sevilla.

ARIAS RODRIGUEZ, Antonio.: El régimen económico y financiero de las universidades públicas. 2004. Edit. Of. de Cooperación Universitaria. Salamanca.

BELFIELD, Clive R.: Economic Principles for Education. Theory and Evidence. 2000. Edward Elgar Publishing. Cheltenham UK.

BRICALL, Joseph M.: Participación de la Sociedad en las Universidades. 2001. En X jornadas de la Asociación de la Economía de la Educación. Murcia. Universidad de Murcia.

BRIDA Juan Gabriel; PEREYRA, Juan Sebastián; SUCH D., María Jesús y ZAPATA A., Sandra.: La contribución del turismo al crecimiento económico. Cuadernos de Turismo, $\mathrm{n}^{\circ}$ 22. 2008. Universidad de Murcia.

BRUCE, Johnston.: Financing Higher Education. Presentación realizada en el año 2003 ante la State University of New York. New York.

BULLOCK, A. D. \& THOMAS H.R.: Schools at the center?: A study of Descentralization”. 1997. London. Routledge.

DOMÉNECH, Rafael.: El impacto económico de la construcción y de la actividad inmobiliaria. BBVA Research. XXX Coloquio Nacional APCE Madrid, 17 de octubre de 2011.

CALERO, Jorge y BONAL, Javier.: Política educativa y gasto público en educación. Aspectos teóricos y una aplicación al caso español. 1999. Ediciones Pomares-Corredor. Barcelona.

CAÑABATE, Antonio y CUERVO, Luis.: Elementos para una propuesta práctica de sistema de financiación de las universidades. En IPIÑAA. y GRAO, J.: Economía de la Educación. Temas de estudio e investigación. Servicio Central de Publicaciones del Gobierno Vasco. 1996. Vitoria.

CCOO (Enseñanza):: Evolución de los presupuestos de universidades públicas 2009 - 2013. Federación de Enseñanzas de Comisiones Obreras. Madrid. 2014.

DÍAZ I.: "El financiamiento de la Educación Superior. Especial referencia a Canarias". En "La organización y el financiamiento de la educación superior en la OCDE: los modelos de mercado burocrático y colegiado" de Becerra J. L.; en "A eficiencia e a equidade no modelo de financiamento do ensino superior universitário público em Portugal: participacao do estado versus participacao das famílias" de Gil. 2002.

EURYDICE. Las cifras claves de la Educación en Europa- 2002. Comisión Europea. Bruselas. Luxemburgo. EUROSTAT. 2003; y de OECD. Education at a Glance. Indicators. Centre for educational research and innovation. Belgium 2003.

EUROPEAN COMMISSION. Study on "The Financing of Higher Education in Europe". December 2004. Belgium. Completed by European Research-Associates (EU-RA). Vol. I.

FERRER, Ferrán.: Educación Comparada. Fundamentos teóricos, metodología y modelos. 1990. Serie Psicopedagógica. Barcelona.

GALÁN Luciano. (Director Proyecto): La corresponsabilidad institucional: estudio de costos para la adaptación del Sistema Universitario Español al Espacio Europeo de Enseñanza Superior. Noviembre 2003. Universidad Autónoma de Madrid. Madrid.

GIL CABRITO, Belmiro.: A eficiencia e a equidade no modelo de financiamento do ensino superior universitário público em Portugal: participacao do Estado versus participacao das famílias. 1996. Universidad Lisboa. Lisboa 
GONZÁLEZ, Pablo.: Elementos Centrales en el Debate de lo Público y lo Privado en Educación. 2001. Mimeo, Departamento de Ingeniería Industrial. Universidad de Chile. Santiago de Chile.

HERNÁNDEZ ARMENTEROS, Juan.: La universidad española en cifras. 2002. Conferencia de rectores de las universidades españolas. CRUE. Madrid.

HERNÁNDEZ DÍAZ, José María.: Estudiantes de los siglos XIX y XX. Aspectos Sociales. En Historia de la Universidad de Salamanca: Estructuras y Flujos. Salamanca. Edic. Universidad Salamanca. 2004.

HOLME-NIELSEN, Lauritz.: Educación Superior. Rasgos de un mercado global para lograr un capital humano avanzado. 2003. Washington. Banco Mundial.

INTERNATIONAL FINANCIAL CORPORATION (IFC).: Financing Education... some innovative trends. Washington. World Bank Group symposium on public and private partnership in education. July. 2004.

JHONES, G.: "The management of universities”. Scottish Journal of Political Economy. No 46. 1999. Edimburg.

MECD. La integración del sistema universitario español en el Espacio Europeo de Enseñanza Superior. Documento-Marco. Editado por el Ministerio de Educación, Cultura y Deporte. Febrero. 2003.

OECD IMHE-HEFCE.: Financial Management And Governance In HEIS: Ireland. Project on International Comparative Higher Education, Financial Management and Governance. 2004.

RAMÍREZ TORRES, Gabriel.: Los modelos de financiación de las instituciones de educación superior públicas en Alemania. Foro de educación. $N^{\circ}$ 7. Salamanca. España. 2008.

RAMIREZ TORRES, Gabriel.: El financiamiento de las universidades públicas en España a inicios del siglo XXI. De las Tercias a las Titulizaciones. Foro de Educación $\mathrm{N}^{\circ} 5$ y 6. Salamanca. 2005.

RODRÍGUEZ CRUZ, Águeda María.: Historia de la Universidad de Salamanca. 1990. Edit. Fundación Ramón Areces. Salamanca.

RODRÍGUEZ GÓMEZ, Roberto.: Los GATS y las Universidades. 2003. Instituto de Investigaciones UNAM. México.

RODRÍGUEZ-SAN PEDRO BEZARES, Luis Enrique y POLO RODRÍGUEZ, Juan Luis.: La hacienda tradicional, siglos XV-XVIII. Edit. Universidad de Salamanca. Salamanca. 2004.

SALAS O., Víctor y ARANDA, Rodrigo F.: Estructura de Aranceles de las Universidades Chilenas. Evolución Reciente y Principales Tendencias. Documento de Trabajo, Departamento de Economía. Universidad de Santiago de Chile. 2003

SÁNCHEZ MARTÍNEZ, Eduardo.: Políticas de financiamiento universitario en Canadá. Tradiciones, transiciones, lecciones de su experiencia. Revista Iberoamericana de Educación. 2002.

VILLAREAL, Enrique.: Eficacia del sistema universitario y mecanismos competitivos de financiación. El financiamiento como instrumento de planificación en un sistema descentralizado. En GRAO, Julio y IPIÑA Alejandro. (Ed.): Economía de la Educación. Temas de Estudio e Investigación. Servicio Central de Publicaciones del Gobierno Vasco. Vitoria. 1996

Association of Universities and Colleges of Canada (AUCC) [Asociación de Universidades y Escuelas Universitarias de Canadá], American Council on Education (ACE) [Consejo Educativo Norteamericano], European University Association (EUA) [Asociación de Universidades Europeas], Council for Higher Education Accreditation (CHEA) [Consejo de Acreditación de la Educación Superior]. 


\section{Leyes consultadas}

Boletín Oficial del Estado (BOE). N 96. De fecha 21/04/2012. Sección I.

Ley 14/1970, de General de Educación y Financiamiento de la Reforma Educativa de fecha 04/08/1970.

Ley Orgánica 11/1983, de Reforma Universitaria. BOE Nº 209 de fecha 01/09/1983.

Ley Orgánica 6/2001, de 21 de diciembre, de Universidades. BOE No 307 de fecha 24/12/2001.

LEY 50/2002, de 26 de Diciembre, de Fundaciones. BOE No 310. de 27/12/2002.

REAL DECRETO Nº 55/2005, de 21 de enero. Publicado en el BOE № 21.

\section{Referencias electrónicas}

http://www.ine.es/jaxi/menu.do?type=pcaxis\&path=\%2Ft13\%2Fp012\&file=inebase \&L=0 Consultado en fecha del 12/06/2014.

BANCO DE ESPAÑA.: http://www.bde.es/webbde/es/estadis/infoest/si_1_4.pdf consultado en fecha 20/03/2014.

BANCO MUNDIAL.: Informe sobre Desarrollo Mundial. 2012. http://siteresources.worldbank.org/INTWDR2012/Resources/7778105-1299699968583/7786210-1315936222006/Complete-Report.pdf consultado en fecha 05/03/2014.

BANCO MUNDIAL.: http://datos.bancomundial.org/indicador/NY.GDP.MKTP.KD.ZG, así como de la encuesta de población activa del Instituto Nacional de Empleo (INEM).

FONDO DE GARANTÍA DE DEPÓSITOS DE ENTIDADES DE CRÉDITO. Consultado en su página electrónica http://www.fgd.es/ es/index.html en fecha 16/03/2014.

http://www.rtve.es/noticias/20120605/crisis-espana-cronologia-desde-2008/533400.shtml consultada en fecha 16/03/2014.

http://www.eleconomista.es/flash/noticias/1167015/04/09/Espana-el-IPC-cae-hasta-una-tasa-interanual-del-01-en-marzo-.html\# . Kku82RMN9R0jtfn. Consultada en fecha 30/03/2014.

http://www.eleconomista.es/mercados-cotizaciones/noticias/1884585/02/10/El-Ibex-35-abre-la-sesion-plano-y-por-debajo-de-los11000-puntos.html\#.Kku81k4dFTNylgi consultada en fecha 05/04/2014.

http://www.rtve.es/noticias/20120605/crisis-espana-cronologia-desde-2008/533400.shtml consultada en fecha 05/04/2014.

http://www.congreso.es/consti/constitucion/indice/sinopsis/sinopsis.jsp?art=135\&tipo=2 consultada en fecha 06/04/201 
